\title{
Production of interleukin 1 by rat pleural leucocytes in culture after intratracheal instillation of crocidolite asbestos
}

Xiao Yang Li, David Lamb, Kenneth Donaldson

\begin{abstract}
This study was undertaken to investigate the production of interleukin 1 (IL-1) by pleural leucocytes in culture and to evaluate the influence of intratracheal instillation of crocidolite asbestos on this production. Normal pleural leucocytes spontaneously released IL-1 in culture and stimulation with lipopolysaccharide (LPS) dramatically increased production. Intratracheal instillation with crocidolite asbestos induced recruitment of pleural leucocytes in the longer term and changed IL-1 production by the leucocytes. Reduced production of IL-1 was found by one day after instillation of asbestos and this was correlated with the dose of asbestos. With increasing time after instillation, however, release of IL-1 by pleural leucocytes gradually recovered to normal until, one month after asbestos injection, the leucocytes produced augmented IL-1 in culture compared with control pleural leucocytes. Our data show that pleural leucocytes possess the potential to produce IL-1 in vitro and this capability is altered by intratracheal instillation of crocidolite asbestos. This may be relevant to development of pleural diseases associated with inhalation of asbestos.
\end{abstract}

(British Journal of Industrial Medicine 1993;50:90-94)

Interleukin 1 (IL-1) belongs to a family of proteins, the interleukins, which are usually described as performing important regulatory functions between

Unit of Respiratory Medicine, Department of Medicine (RIE), The University of Edinburgh, City Hosptal, Greenbank Drive, Edinburgh EH10 5SB, UK

X Y Li

University of Edinburgh, Department of Pathology, Teviot Place, Edinburgh, UK

D Lamb

Institute of Occupational Medicine, 8 Roxburgh Place, Edinburgh EH8 9SU, UK

K Donaldson leucocytes. ${ }^{1}$ Mononuclear phagocytes seem to be the major producers of IL-1, although other cells, including reticulum cells, endothelial cells, and neutrophils also produce IL-2. ${ }^{23}$ Although small amounts may be released spontaneously, most normal macrophages produce IL-1 only in response to exogenous stimulants such as microbial toxins, inflammatory agents, complement, and clotting components. ${ }^{4}$ Interleukin 1 possesses a wide spectrum of immunological and non-immunological activities including tissue remodelling, repair, and inflammation, by helping to coordinate the activities of many cell types. ${ }^{56}$

Asbestos has been in widespread industrial use for a long time ${ }^{7}$ and a large body of evidence has confirmed that inhaled asbestos is associated with many lung disorders such as parenchymal fibrosis (asbestosis) and bronchial carcinoma. ${ }^{8}$ The roles of IL-1 in asbestos related lung disorders have been investigated and studies have shown that exposure to asbestos results in abnormal release of IL-1 by macrophages. $^{910}$

Pleural pathological processes, such as effusion, pleural plaques, pleural fibrosis, and mesothelioma, ${ }^{11}$ are seen in a proportion of asbestos exposed persons. The effects of asebestos on the activity of pleural leucocytes have not, however, received much attention. Very little is known about the role of cytokines in pleural pathology caused by fibrous dusts such as asbestos.

The objective of this investigation was to study the ability of pleural leucocytes to produce IL-1 in vitro and to assess the influence of crocidolite asbestos, given intratracheally, on this production.

\section{Materials and methods}

\section{ANIMALS}

Syngeneic PVG rats more than 12 weeks old were obtained from the Institute of Occupational Medicine animal unit.

INTRATRACHEAL INSTILLATION AND PLEURAL LAVAGE Rats were injected intratracheally with $0.5 \mathrm{ml}$ of phosphate buffered saline (PBS) containing from $1 \mathrm{mg}$ to $10 \mathrm{mg}$ UICC crocidolite asbestos. At different periods after infection, rats were killed by 
injection of Nembutal (Ceva, Watford) and the chest wall was exposed. After insertion of a blunt needle into the pleural cavity between two lower ribs, four sequential $5 \mathrm{ml}$ volumes of PBS were injected into the cavity and the chest wall was gently massaged before withdrawal. The cell suspension from the lavage was pooled in plastic containers and kept on ice.

PREPARATIONS OF CELLS AND SUPERNATANTS

The pleural leucocytes were centrifuged and resuspended in F10 medium (Gibco, Paisley) plus $2 \%$ bovine serum albumin (BSA, Sigma, Poole). The total cell number from each rat was assessed in a Neubauer chamber. The proportion of each cell type was obtained by staining cytocentrifuge smears with Diff-Quik (Merz-dade, Dudingen, Switzerland).

Pleural leucocyte supernatants were obtained by resuspending the cells at $1 \times 10^{6} \mathrm{cell} / \mathrm{ml}$ in $\mathrm{F} 10$ medium plus $2 \%$ BSA. The cells were incubated at $37^{\circ} \mathrm{C}$ in $5 \% \mathrm{CO}_{2}$ for 24 hours. Supernatant fluids were collected and spun at $3000 \mathrm{rpm}$ to clarity, then aliquoted and stored at $-70^{\circ} \mathrm{C}$ before assay. When required lipopolysaccharide (LPS, Sigma, Poole) was added into cell cultures at $100 \mathrm{ng} / \mathrm{ml}$.

\section{ASSAY FOR IL-1 ACTIVITY}

The IL-1 activity of supernatant fluids was assessed by using the standard mouse thymocyte proliferation assay as described by Mizel. ${ }^{12}$ Thymocytes obtained from three to six week ald $\mathrm{C} 3 \mathrm{H}$ mice at $0.6 \times 10^{6}$ cells per well were incubated in RPMI-1640 medium (Gibco, Paisley) supplemented with $10 \%$ fetal calf serum (FCS, Gibco, Paisley) and $20 \mu \mathrm{M}$ 2-mecaptoethanol (Sigma, Poole) or in test supernatants diluted with the medium at $37^{\circ} \mathrm{C}$, under $5 \% \mathrm{CO}_{2}$ for 72 hours. Proliferation was assessed in the presence of a suboptimal dose $(5 \mu \mathrm{g} / \mathrm{ml})$ of phytohaemagglutinin (PHA, Sigma, Poole). Sixteen hours before the end of the incubation period thymocytes were labelled with $9 \cdot 25 \mathrm{KBq}^{3} \mathrm{H}$-methylthymidine (Amersham International, Aylesbury Buckinghamshire) and harvested on glass fibre filters. The filters were dried and the cellular thymidine incorporation was measured by liquid scintillometry in a $\beta$ counter. The activity of test samples was calculated by comparison with the standard curve of a series of dilutions of IL-1 $\beta$ standard (a gift from Dr D Burnett, Lung Immunobiochemical Research Laboratory, General Hospital, Birmingham).

\section{ASSAY FOR IL-2 ACTIVITY}

The IL-2 was assayed using the IL-2 dependent CTLL-2 cell line. The CTLL-2 cells were maintained in RPMI 1640 medium with $10 \%$ FCS as well as $5 \%$ of $\mathrm{IL-2}$ enriched rat splenocyte supernatant. When required the cells were washed thoroughly and then suspended in RPMI 1640 medium supplemen- ted with $10 \%$ FCS. Fifty $\mu$ l of cell suspension containing $5 \times 10^{3}$ cells and $50 \mu \mathrm{l}$ of test supernatants were dispensed into each well of the microtitre plate and then incubated for 24 hours at $37^{\circ} \mathrm{C}$ under $5 \% \mathrm{CO}_{2}$. Proliferation of CTLL-2 cells was assayed by the uptake of tritiated thymidine as described and compared with the IL-2 standard.

\section{ENDOTOXIN MEASUREMENT}

To determine whether the background release of IL1 by normal pleural leucocytes in vitro was caused by low concentrations of endotoxin in the media or serum used in the assay, a kit (COATEST, KABI Diagnostica, KabiVitram Ltd, Uxbridge, Middx) was used to detect the endotoxin concentrations in all media used in the study.

\section{STATISTICS}

Multiple repeat experiments were carried out and results were subjected to analysis of variance. When there was a significant $F$ value for the effect of treatment, individual means were compared for significance using $t$ tests. ${ }^{13}$

\section{Results}

PLEURAL LEUCOCYTE POPULATIONS

Normal pleural leucococytes were composed mainly of four types of cells: macrophages, mast cells, eosinophils, and lymphocytes, most cells being macrophages (table 1).

Table 2 shows that with increasing time after the intratracheal injection of $5 \mathrm{mg}$ crocidolite asbestos, the total cell numbers of pleural leucocytes increased significantly compared with those of leucocytes from normal pleura. Considering the change in the proportion of different cell types, the percentage of macrophages declined after injection of asbestos whereas the proportion of eosinophils increased significantly. Other cell types remained at the same level; neutrophils were rarely seen in any of the populations of pleural leucocytes.

The most significant difference arose in that a small number of neutrophils appeared in the pleural cell population when the doses of intratracheally injected crocidolite increased up to $10 \mathrm{mg}$; however, there were no obvious differences among total cell numbers and the percentages of other components of pleural leucocytes (table 3 ).

Table 1 Proportions of normal pleural leucocytes

\begin{tabular}{|c|c|c|c|c|}
\hline \multirow{2}{*}{$\begin{array}{l}\text { Total } \\
\text { number } \\
\left(\times 10^{6}\right)\end{array}$} & \multicolumn{4}{|l|}{ Percentage } \\
\hline & Macrophages & Lymphocytes & Mast cells & Eosinophils \\
\hline $4.51(0.29)$ & $82(1.55)$ & $1(0 \cdot 34)$ & $11(1 \cdot 50)$ & $6(0 \cdot 77)$ \\
\hline
\end{tabular}

Results are mean (SEM); $n=14$ rats. 
Table 2 Cell populations of pleural leucocytes after intratracheal instillation of $5 \mathrm{mg}$ crocidolite asbestos

\begin{tabular}{|c|c|c|c|c|c|c|}
\hline \multirow[b]{2}{*}{ Time (day) } & \multirow[b]{2}{*}{ Total no $\left(\times 10^{6}\right)$} & \multicolumn{5}{|l|}{ Percentage } \\
\hline & & Macrophages & Neutrophils & Lymphocytes & Mast cells & Eosinophils \\
\hline $\begin{array}{r}1 \\
3 \\
14 \\
30\end{array}$ & $\begin{array}{l}4.54(0.30) \\
6.30(0.73)^{\star} \\
6.92(0.60)^{\star \star} \\
6.96(2.08)^{\star \star}\end{array}$ & $\begin{array}{l}78(1 \cdot 1)^{\star} \\
76(1 \cdot 5)^{\star \star} \\
72(3 \cdot 0)^{\star \star} \\
75(1 \cdot 8)^{\star \star}\end{array}$ & $\begin{array}{l}0 \\
0 \\
0 \\
0\end{array}$ & $\begin{array}{l}1(0 \cdot 3) \\
2(0.8) \\
1(0.5) \\
1(0.4)\end{array}$ & $\begin{array}{r}12(1 \cdot 5) \\
9(1.4) \\
9(2 \cdot 1) \\
9(1 \cdot 5)\end{array}$ & $\begin{array}{c}9(0.9)^{\star} \\
13(1.5)^{\star \star \star} \\
18(1.4)^{\star \star \star} \\
15(0.7)^{\star \star \star}\end{array}$ \\
\hline
\end{tabular}

Results are mean (SEM); $\mathrm{n}=5-7$ rats.

${ }^{\star} p<0.05 ;{ }^{\star \star} p<0.01 ;{ }^{\star \star \star} p<0.001$ compared with controls.

Table 3 Pleural leucocyte populations one day after intratracheal instillation of different doses of crocidolits asbestos

\begin{tabular}{|c|c|c|c|c|c|c|}
\hline \multirow[b]{2}{*}{ Dose ( $m g$ ) } & \multirow[b]{2}{*}{ Total no $\left(\times 10^{6}\right)$} & \multicolumn{5}{|l|}{ Percentage } \\
\hline & & Macrophages & Neutrophils & Lymphocytes & Mast cells & Eosinophils \\
\hline $\begin{array}{r}1 \\
5 \\
10\end{array}$ & $\begin{array}{l}4.83(0.22) \\
4.54(0.30) \\
4.78(0.21)\end{array}$ & $\begin{array}{l}79(1 \cdot 2) \\
78(1 \cdot 1) \\
78(0 \cdot 9)\end{array}$ & $\begin{array}{l}0 \\
0 \\
2(0.9)\end{array}$ & $\begin{array}{l}2(1.0) \\
1(0.3) \\
1(0.4)\end{array}$ & $\begin{array}{l}10(1 \cdot 5) \\
12(1 \cdot 5) \\
10(1 \cdot 2)\end{array}$ & $\begin{array}{l}8(0 \cdot 8)^{\star} \\
9(0 \cdot 9)^{\star} \\
9(0 \cdot 7)^{\star \star}\end{array}$ \\
\hline
\end{tabular}

Results are mean (SEM); $n=5-7$ rats.

${ }^{\star} p<0.05 ;{ }^{\star \star} p<0.01$ compared with controls.

PRODUCTION OF IL-1 BY NORMAL PLEURAL

LEUCOCYTES WITH AND WITHOUT LPS STIMULATION

Figure 1 shows that leucocytes from normal pleura produced IL-1 activity in culture, even in the absence of stimulation by endotoxin. The activity of IL-1 in supernatants of normal leucocytes without stimulation was about $167 \mathrm{U} / \mathrm{ml}$ compared with IL$1 \beta$ standard. After stimulation with $100 \mathrm{ng} / \mathrm{ml}$ of LPS, the activity of IL- 1 reached about $268 \mathrm{U} / \mathrm{ml}$, roughly double the normal values. At the highest concentration of LPS stimulated supernatant (1:4) the abnormal reduction of IL- 1 activity might be due to too high a concentration of IL-1 in the supernatant, which inhibits the mitogenesis of $\mathrm{C} 3 \mathrm{H}$ mouse thymocytes.

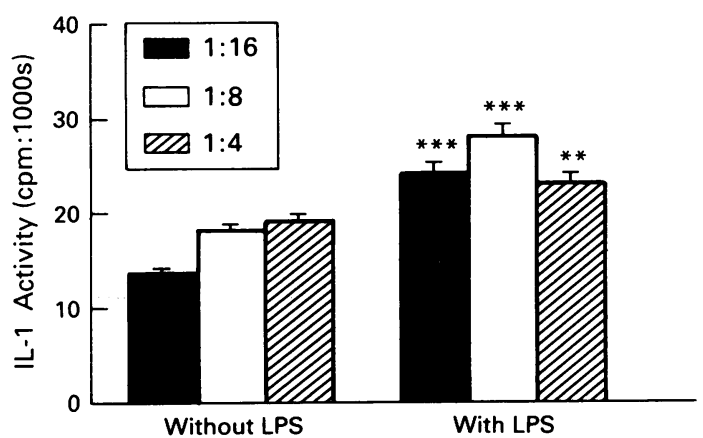

Figure 1 Production of IL-1 by pleural leucocytes with or without stimulation with LPS. Results are presented as mean (SEM) of 10-14 separate experiments performed in triplicate. Asterisks denote a significant difference from corresponding dilution of controls: ${ }^{\star \star} p<0.01$; $\star \star \star p<0.001$.
The measurement of endotoxin in media used in the study indicated a small contamination of endotoxin: $\mathrm{F} 10+2 \%$ BSA contained $106 \mathrm{pg} / \mathrm{ml}$ and PBS $16 \mathrm{pg} / \mathrm{ml}$ of endotoxin. There was no detectable endotoxin in RPMI-1640 + 10\% FCS and saline.

\section{RELEASE OF IL-1 BY CULTURED PLEURAL LEUCOCYTES FROM RATS INTRATRACHEALLY INSTILLED WITH CROCIDOLITE ASBESTOS}

Intratracheal instillation of $5 \mathrm{mg}$ crocidolite asbestos resulted in a decrease in activity of IL-1 in the supernatants (fig 2). One day after injection of asbestos, the IL-1 activity decreased significantly.

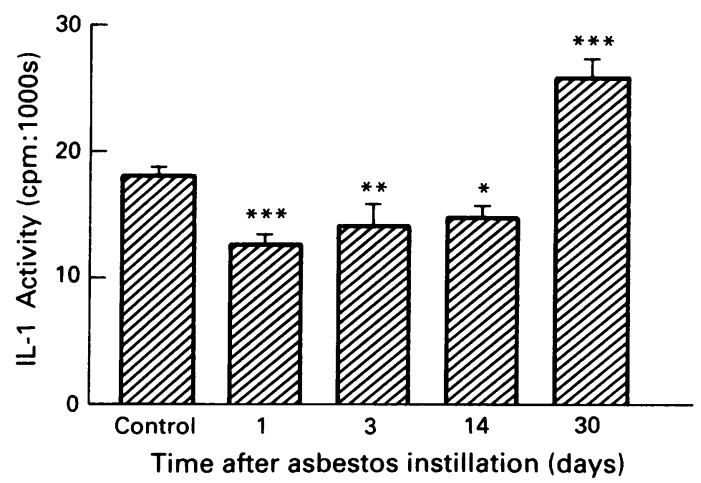

Figure 2 Production of IL-1 by pleural leucocytes from rats at various times after intratracheal instillation of $5 \mathrm{mg}$ crocidolite asbestos. Each column represents mean (SEM) of triplicate wells in 9-15 separate experiments. Dilution of pleural leucocyte supernatant is $1: 8$. Asterisks denote a significant difference from controls: ${ }^{\star} p<0.05 ;{ }^{\star \star} p<0.01$; $\star \star \star p<0.001$. 


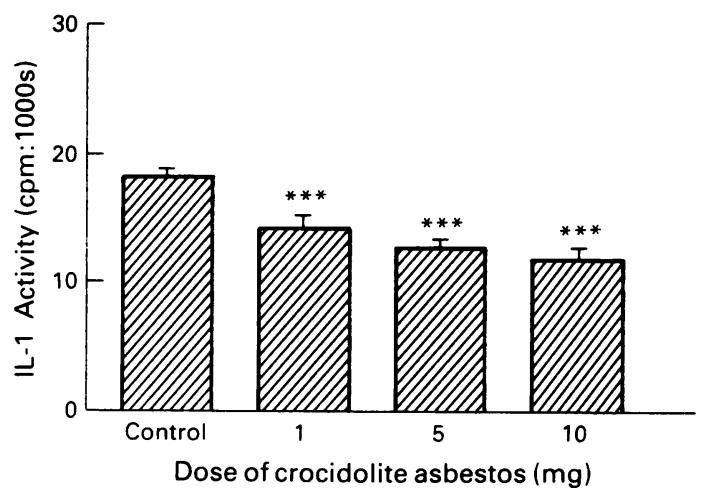

Figure 3 Production of IL-1 by pleural leucocytes from rats one day after intratracheal instillation of different doses of crocidolite asbestos. Each column represents mean (SEM) of triplicate wells in 9-16 separate experiments. Dilution of pleural leucocyte supernatant is $1: 8$. Asterisks denote a significant difference from controls: ${ }^{\star \star \star} p<0.001$.

With increasing time after instillation, the activity of IL-1 recovered towards normal. Moreover, IL-1 activity in the supernatants was significantly higher than control values by 30 days after instillation.

Figure 3 shows the dose related effect of instilled asbestos on production of IL-1 by pleural leucocytes in culture. The decrease in activity of IL-1 was correlated with the increase in the dose of injected asbestos.

\section{MEASUREMENT OF IL-2 ACTIVITY}

To rule out IL-2 as a factor in the thymocyte assay, ${ }^{14}$ IL-2 activity was measured with the IL-2 dependent CTLL-2 cell line. Assays of pleural leucocyte supernatants maximally stimulating $\mathrm{C} 3 \mathrm{H}$ thymocytes failed to show detectable amounts of IL-2 when tested for their capacity to support CTLL-2 cell growth (data not shown).

\section{Discussion}

Although a large body of work has been carried out on production of IL-1 by monocytes and macrophages, ${ }^{1}$ few studies have been carried out on pleural leucocytes in this regard. In view of the important role of the pleura in basic lung function and the pleural pathology caused by fibrous dusts, we were interested in the functions of pleural leucocytes after exposure of the airspace to asbestos.

The present study indicates that, without added stimulation, pleural leucocytes from normal rats produced IL-1 in culture. When stimulated with LPS this production increased considerably. Production of IL-1 was decreased when rats received intratracheal administration of crocidolite asbestos and this effect was related to the dose of asbestos in the lungs. With increasing time after instillation of asbestos, IL-1 production by the leucocytes returned to normal and was increased over the control values by one month after the instillation.

It has been reported that most normal cell types and some cell lines produce IL-1 only in response to various stimulants. ${ }^{15}$ Production of IL-1 by normal cells can probably be attributed to a continuing response to previous stimulation in vivo or alternatively, the presence of contaminating endotoxin.

Culture media, blood separation media, FCS, and organic buffer used in culturing IL-1 producing cells may contain endotoxin, depending on the source. ${ }^{16}$ In the present study, low concentrations of contaminating endotoxin were detected, which may contribute to spontaneous production of IL-1 in culture. Despite this background release of IL-1, however, the leucocytes could still be stimulated with LPS to release considerably more IL-1 in culture than controls, which indicates the extensive potential for production of IL-1 by the cells.

The present study indicates that the increased production of IL-1 is concurrent with the recruitment of pleural leucocytes into the pleural space with increasing time after instillation of asbestos. It has been reported that normal alveolar macrophages are at least 1000 times less sensitive to LPS in terms of IL-1 release than blood monocytes. Also, denser alveolar macrophages and blood monocytes released more IL-1 than the less dense components; this dense population is considered to be the less mature monocytic population. ${ }^{17} 18$ If young mononuclear phagocytes are the prime source of IL-1, IL-1 release in the pleural space may be regulated, at least in part, by factors that control the influx of young monocytes. In fact, our results show a persistent recruitment of pleural leucocytes with increasing time after exposure to asbestos. As these monocytic cells are continuously recruited into the pleural space, eventually the IL-1 activity released by those cells may exceed control values, as shown in the study.

The changed pattern of release of pleural leucocyte IL-1 at different stages after deposition of asbestos in the airspace cannot be fully explained by changes in cell populations. We presume, therefore, that the difference in IL-1 production is a result of alteration in cellular activity. Pleural leucocytes are sensitive to stimulation to produce cytokine during culture and, after intratracheal instillation of asbestos in vivo this potential may be modulated or impaired by asbestos fibre in the lungs.

Increasing dose of injected crocidolite resulted in slight changes to the pleural cell population with the appearance of a few neutrophils in the pleural space at the highest dose. A dose related decrease in IL-1 production by the leucocytes was, however, present. Because we failed to detect migration of asbestos fibres or other similar size particles into the pleural space after intratracheal instillation, ${ }^{19}$ we suggest that the inflammation caused by asbestos in the airspaces 
may cause the transfer of as yet unidentified inflammatory mediators to the pleural cavity. These may down regulate the ability of pleural leucocytes to release IL-1 in culture.

Normally, there is increased IL-1 release by macrophages exposed to asbestos. Kagan et al ${ }^{10}$ showed that inhalation of either crocidolite or chrysotile asbestos in rats was associated with augmented release of IL-1 by alveolar macrophages. An in vitro study also showed that exposure of peritoneal macrophages to chrysotile asbestos resulted in increased intracellular IL-1 in those cells. ${ }^{9}$ Long amosite asbestos also stimulates increased release of the cytokine tumour necrosis factor compared to short amosite. ${ }^{20}$

In the present study we have shown that asbestos in the airspace results in a decrease in the IL-1 secreting activity of pleural cells. Because deposition of asbestos in the airspace also suppressed production of tumour necrosis factor by pleural leucocytes in culture, ${ }^{19}$ this suppression may have some general selective value in the pleural space. Our data on the increased production of plasminogen activator inhibitor after the same type of asbestos treatment ${ }^{21}$ confirms that the effect is not a general inhibition but suggests that there is selective inhibition of cytokine production by the macrophages. The potency of prostaglandin $E_{2}$ in inhibiting secretion of IL- $1^{22}$ suggests an autocrine role for this substance.

In the longer term, IL-1 production by pleural leucocytes was increased and this may partly explain the pleural pathology, such as pleural adhesion and pleural fibrosis, seen in persons exposed long term to asbestos. ${ }^{11}$ Fibroblasts and their functions, such as raised rates of synthesis of collagen, prostaglandin production, and fibroblast migration, may be stimulated by IL-1..$^{523}$ Thus the long term increase in production of IL-1 could lead to fibroplasia in the pleura. Increased production of plasminogen activator inhibitor by pleural leucocytes, which we have also shown in the same model, ${ }^{21}$ could produce a fibrous matrix for fibroblast growth that would encourage fibrous tissue growth.

In summary, the ability of pleural leucocytes to produce IL-1 in culture showed a dose dependent decrease in the acute period after exposure to asbestos; the pleural leucocytes obtained a longer time after exposure, however, showed augmented ability to produce IL-1. These complex changes in production of IL-1 by pleural leucocytes are not understood but may be related to the pleural pathology seen after exposure to asbestos.

Requests for reprints to: K Donaldson, Institute of Occupational Medicine, 8 Roxburgh Place, Edinburgh EH8 9SU, UK.
1 Martin M, Resch K. Interleukin 1: more than a mediator between leukocytes. Trends in Pharmacological Science 1988; 9:171-7.

2 Bendtzen K. IL-1, IL-6 and TNF in infection, inflammation and immunity. Immunol Lett 1988;19:183-92.

3 Ohkawara S, Goto F, Yoshiraga M. IL-1 as an inflammatory hormone. Acta Pathologica Japonica 1989;39:85-100.

4 Dinarello CA. Interleukin-1 and its related cytolines. In: Sorg C, ed. Macrophage-derived cell regulatory factors, cytokines. Vol 1 . Basel: Karger, 1989;vol 1:105-54.

5 Postlethwaite AE, Raghav R, Stricklin GP, Poppleton H, Sejer JM, Kang AH. Modulation of fibroblast function by interleukin 1: increased steady-state accumulation of type I procollagen messenger RNAs and stimulation of other functions but not chemotaxis by human recombinant interleukin 1 alpha and beta. $J$ Cell Biol 1988;106:311-8.

6 Schmidt JA, Mizel SB, Cohen D, Green I. Interleukin 1, a potential regulator of fibroblast proliferation. J Immunol 1982; 128:2177-82.

7 Wagner JC. Mineral fibres and mesothelioma. Thorax 1986;41: $161-6$.

8 Seaton A. Asbestos-related diseases. In: Morgan WKC, Seaton A, eds. Occupational lung diseases. London: W B Saunders Co, 1984:323-76.

9 Godelaine D, Beaufay $\mathrm{H}$. Comparative study of the effect of chrysotile, quartz and rutile on the relese of lymphocyteactivating factor (interleukin 1) by murine peritoneal macrophages in vitro. In: Bignon J, Peto J, Saracci R, eds. Nonoccupational exposure to mineral fibres. Lyon: IARC Scientific Publications, 1989;90:149-55.

10 Kagan E, Georgian MM, Hartmann DP. Enhanced interleukin production and alveolar macrophage Ia expression after asbestos inhalation. In: Beck EC, Bignon J, eds. Vitro effects of mineral dusts. Third international workshop, Berlin, SpringerBerlag, 1985:149-57.

11 Herbert A. Pathogenesis of pleurisy, pleural fibrosis, and mesothelial proliberation. Thorax 1986;41:176-89.

12 Mizel S. Production and quantitation of lymphocyte activating factor (interleukin 1). In: Herscowitz $\mathrm{HB}$, Holden $\mathrm{HT}$, Bellanti JA, Ghaffer A, eds. Manual of macrophage methodology. New York: Marcel Dekker, 1981:329-36.

13 Ryan BF, Joiner BL, Ryan TA. Minitab handbook. 2nd ed. Boston: Duxbury Press, 1985.

14 Gerrard TL, Siegel JP,Dyer DR, Zoon KC. Differential effects of interferon-a and interferon-r on interleukin 1 secretion by monocytes. J Immunol 1987;138:2535-40.

15 Oppenheim JJ, Kovacs EJ, Matsushima K, Duram SK. There is more than one interleukin 1. Immunology Today 1986;7:45-56.

16 Dinarello CA. Interleukin 1. Rev Infect Dis 1984;6:51-95.

17 Wewers MD, Rennard SI, Hance AJ, Bitterman PB, Grystal RG. Normal human alveolar macrophages obtained by bronchoalveolar lavage have a limited capacity to release IL-1. $J$ Clin Invest 1984;74:2208-18.

18 Elias JA, Schreiber AD, Gustilo K, et al. Differential interleukin 1 elaboration by unfractionated and density fractionated human alveolar macrophages and blood monocytes: relationship to cell maturity. J Immunol 1985;135:3198-204.

$19 \mathrm{Li} \mathrm{XY}$, Lamb $\mathrm{D}$, Donaldson $\mathrm{K}$. Intratracheal injection of crocidolite asbestos depresses the high secretion of tumor necrosis factor by pleural leukocytes in vitro. Exp Lung Res 1992;18:359-72.

20 Donaldson K, Szyamaniec S, Li XY, Brown DM, Brown GM. Inflammation and immunomodulation caused by short and long amosite asbestos samples. In: Brown RC, Hoskins J, eds. Mechanisms in fibre carcinogenesis. New York: Plenum Press, 1991:121-30.

$21 \mathrm{Li} \mathrm{XY,} \mathrm{Brown} \mathrm{GM,} \mathrm{Lamb} \mathrm{D,} \mathrm{Donaldson} \mathrm{K.} \mathrm{Increased} \mathrm{produc-}$ tion of plasminogen activator inhibitor in vitro by pleural leukocytes from rats intratracheally instilled with crocidolite asbestos. Environ Res 1991;55:135-44.

22 Larrick JW, Kunkel SL. The role of tumor necrosis factor and interleukin 1 in the immunoinflammatory response. Pharmaceutical Research 1988;5:129-39.

23 Kahari V-M, Heino J, Vuorio E. Interleukin 1 increases collagen production and mRNA levels in culture skin fibroblasts. Biochimica et Biophysica Acta 1987;929:142-7.

Accepted 2 March 1992 